\title{
Plant grafting and its application in biological research
}

\author{
WANG YouQun \\ State Key Laboratory of Plant Physiology and Biochemistry, College of Biological Sciences, China Agricultural University, Beijing 100193, China
}

Received June 15, 2011; accepted September 1, 2011

\begin{abstract}
Grafting is widely used for various aspects of plant biological research. We reviewed grafting methods and graft development processes for herbaceous plants. We introduced also methods of investigating the development of graft union and compatibility, and the application of grafting in understanding translocation of substances and long-distance signaling in plants.
\end{abstract}

grafting, translocation of substances, long-distance signaling

Citation: Wang Y Q. Plant grafting and its application in biological research. Chinese Sci Bull, 2011, 56: 3511-3517, doi: 10.1007/s11434-011-4816-1

Plant grafting originated during the 'Warring States' period of China's history, and is thus more than two thousand years old. During its long history, grafting techniques have been continuously developed and improved. Today, grafting is commonly used as a routine method of asexual reproduction for the agricultural production of many types of plant, including fruit trees, vegetables and flowers. It may be used to enhance resistance, improve quality, and increase production. It has therefore brought enormous economic benefits to agricultural production.

Grafting is the method of purposively combining the buds or branches of one plant with the roots and base of another plant. The upper component is the 'scion', and the lower is the 'rootstock' or 'stock'. 'Autografting' is grafting between the same plants of the same species; 'homografting' is grafting between different plants of same species; 'heterografting' is grafting between plants of different species [1]. The grafting combinations used in agricultural production are commonly compatible, as both scion and rootstock survive after grafting and grow normally until flowering [2]. Most heterografting combinations are incompatible as either scion or rootstock, and both may die after grafting.

Grafting has been widely used to study transport of substances within plant tissues, flowering regulation, and signal

email: wangyq@cau.edu.cn transduction mechanisms. We reviewed grafting methods, graft union development, and grafting applications in plant biological research.

\section{Grafting methods}

Grafting is commonly performed at plant stems using flat, cleft, and approach methods, among which cleft grafting is the most commonly used. In cleft grafting, the scion base is cut into a wedge shape. The rootstock is first sliced horizontally and then cut into a cleft. The scion is inserted into the cleft in the rootstock. Flat grafting is commonly used in studies of graft union development. In flat grafting, both the scion and the rootstock are cut into flat surfaces, and are grafted together. In approach grafting, the cambium of the scion and rootstock are exposed by cutting the epidermis and cortex. The surfaces are then combined. To successfully perform grafting, the precise docking of anatomical structures between scion and rootstock is very important. Dislocation of vascular system and cambium often leads to graft failure or delayed development [3].

For different research purposes, a variety of other grafting methods have been introduced, including callus grafting, grafting of an explanted stem segment in vitro, and micrografting.

To study cytological events during incompatible grafting, 
Moore and Walker [4] performed in vitro callus grafting between Solanum pennellii and Sedum telephoides; they found that the cells near the graft union had dilated endoplasmic reticulum and thickened cell walls. A co-suspension culture of pear (Pyrus communis) and quince (Cydonia oblonga) callus resulted in significant reduction in quince growth [5].

Gebhardt and Goldbach [6] established a micrografting method using plantlets obtained from tissue culture of Prunus shoot-tips under sterile conditions, and cultured the grafted plantlets in vitro in liquid medium. Russo and Slack [7] introduced a method to screen and analyze virus-resistant potato cultivars by grafting potato plantlets in vitro.

Parkinson and Yeoman [8] introduced an in vitro grafting method using explanted stem segments. They cut a part of a plant stem into segments, grafted these together, and cultured them in sterile MS medium. To simulate normal physiological conditions, the medium was divided into two parts. The medium in contact with the scion was supplemented with sucrose, auxin, and cytokinin at particular concentrations, while the medium in contact with the rootstock was only supplemented with cytokinin. Since it is easy to change media composition and culture conditions, this method has been used to explore the impacts of different factors and conditions on graft compatibility and physiological function [9].

Arabidopsis thaliana has been widely used as a model plant in the study of plant genetics, developmental biology, and molecular biology. The grafting of A. thaliana using different combinations has been used to investigate transport of substances, signal transduction, floral induction, systemic resistance, and abiotic stress response [10,11]. A. thaliana has rosette leaves, and its most suitable grafting positions are the inflorescence stem and the hypocotyl. Grafting of an inflorescence stem has usually been performed using cleft and flat grafting methods $[10,12]$. A few days after bolting, the inflorescence stem is cut with a razor. The grafting site is rapidly covered with silicone from a tube, to ensure that the scion is closely connected with the rootstock. Turnbull et al. [11] first established a hypocotyl grafting system in Arabidopsis thaliana using seedlings grown in petri dishes. They cut the hypocotyl of seedlings under a stereomicroscope, and used these for autografting or homografting. Grafting during bolting is convenient because the inflorescence stem diameter is relatively thick. However, during this period, A. thaliana has completed most of its important physiological development including the induction of flower organs. Though hypocotyl grafting is relatively difficult, this grafting system is more suitable for the study of substance and signal exchanges between roots and shoots. Rhee and Somerville [12] performed preliminary studies of the histology of the graft union from inflorescence stems. The detailed development process of Arabidopsis thaliana grafting has not been well studied, however. Determining when the vascular tissue connection between scion and rootstock takes place, is very important in understanding how signals are transducted and substances are transported.

\section{Graft union development in herbaceous plants}

The developmental process in compatible grafting of herbaceous plants roughly includes: (1) the formation of the isolation layer and the initial adhesion of scion and rootstock, (2) the formation of the wound callus, and (3) reconnection of the vascular bridge between scion and rootstock $[13,14]$.

\subsection{Isolation layer formation and initial adhesion be- tween scion and rootstock}

Cutting during the grafting process can lead to the formation of an isolation layer, also known as a necrotic layer. Observation under an electron microscope has indicated that the isolation layer is composed of the remaining cell walls of cutting-induced dead cells and surrounding substances with a high electron density [15,16]. The initial adhesion between scion and rootstock has been observed to occur $1 \mathrm{~d}$ after grafting, and is related to a pronounced dictyosome activity in cells near the graft interface [16]. During the early stages of grafting, the isolation layer is distributed over the whole graft interface. With the formation of the callus, the isolation layer is disrupted in the vascular area, and is then gradually extended. Thus, scion and rootstock are able to directly connect. Lastly, the isolation layer disappears, mainly because of growth pressures caused by the callus dividing at both sides of the graft union, and by callus absorption [17].

\subsection{Formation of the wound callus}

Two to three days after grafting, the wound callus is formed by division of the parenchyma cells from cambium, phloem, xylem, and pith near the wounded surface. In herbaceous plants, callus cells are first formed at vascular bundles and cortex, with only a few in the pith $[14,15,17]$. Mixing of the wound callus cells of both graft partners can lead to further connection between scion and rootstock.

With the formation of the callus, plasmodesmata are formed between scion and rootstock cells in the thinning region of the isolation layer. Because the plasmodesmata are formed in non-dividing cell walls, they are considered secondary plasmodesmata. Kollmann and Glockmann [18] accurately distinguished the contacting cell walls in a Vicia faba/Helianthus annuus graft based on ultrastructural features, and confirmed the presence of secondary plasmodesmata between rootstock and scion. The secondary plasmodesmata are able to connect cells between rootstock and scion to form a continuous symplast. Thus, substance exchange between adjacent cells and cell communication can be achieved. These may play important roles in the further 
development of the graft union. Wang [9] found that no plasmodesmata were formed between scion and rootstock in incompatible Vicia faba/Helianthus tuberosus graft, and the phloem of scion and rootstock were not connected.

\subsection{Formation of wound repair vascular bridges be- tween scion and rootstock}

Formation of wound repair vascular bridges between scion and rootstock is a critical developmental event in compatible grafting [2]. In herbaceous plant grafting, differentiation of xylem elements can be observed in the wound callus $3 \mathrm{~d}$ after grafting. These newly formed xylem elements are irregular in shape and generally directly differentiate from callus cells at the graft union or parenchyma cells around vascular bundles [17,19]. Four days after a pea (Pisum sativum) autograft, xylem elements were differentiated from the callus cells of both scion and rootstock. Seven days after grafting, wound repair xylem bridges connecting vascular bundles of scion and rootstock were observed [17]. Similarly, formation of wound xylem bridges was also observed in Vicia faba and Nicandra physaloides autografts of explanted stem segments, $5 \mathrm{~d}$ after grafting [20]. Monzer and Kollmann [21] identified xylary connections within a graft based on species-specific secondary wall thickenings in a Lophophora williamsii/Trichocereus spachianus heterograft.

Before differentiating into wound sieve elements, callus and parenchyma cells at the graft union normally divide one to several times to form sieve elements and companion cells $[15,20,22]$. In a pea autograft $5 \mathrm{~d}$ after grafting, callus cells of scion and rootstock differentiated into sieve elements. Eight days after grafting, wound repair phloem bridges connecting scion and rootstock were observed [17]. In a $\mathrm{Cu}$ cumis sativus/Cucurbita ficifolia heterograft, wound phloem bridges were established at the graft union $7 \mathrm{~d}$ after grafting. The average number of sieve tube connections in a heterograft of Cucumis sativus/Cucurbita ficifolia was significantly lower than in the respective homograft, Cucumis/ Cucumis [15]. In an explanted stem grafting system, wound phloem bridges in autografts of Vicia faba and Nicandra physaloides were observed $5 \mathrm{~d}$ after grafting. Those within a heterograft of Nicandra physaloides/Lycopersicon esculentum were observed $7 \mathrm{~d}$ after grafting [20]. In a Vicia faba/Helianthus annuus heterograft, specific cell markers were used to distinguish sieve elements of scion and rootstock. Sieve elements of Vicia faba were found to contain P-type plastids with starch and protein, while those of $\mathrm{He}$ lianthus annuus contained S-type plastids with only starch. These cell markers were used to accurately identify the interspecific sieve plates between Vicia faba and Helianthus annuus graft partners [22].

As wound repair xylem and phloem elements further differentiate within the graft union, a newly formed wound cambium can eventually develop between them and give rise to new phloem and xylem strands $[14,16]$. In herba- ceous plants, wound cambium is often formed two to three weeks after grafting. The formation of wound cambium crossing the graft union is often considered a sign of the completion of the graft union [14,22].

Studies of autografts of explanted stem segments of Nicandra physaloides and Vicia faba have shown that the development of grafting in vitro is similar to that in vivo $[9,20]$. Given the consistency of culture conditions, explanted stem segment grafting is more suitable for biochemical and physiological research than grafting in vivo. A new way to study compatible or incompatible mechanisms of grafting is thus available.

Grafting success is influenced by genetics, structure, growth characteristics, physiological, and biochemical factors. Among these, genetic factors are critical for compatibility. In general, the closer the taxonomic relationship between scion and rootstock, the higher the grafting success rate. In most incompatible graft combinations, vascular continuity is not established between scion and rootstock [23]. Physiological factors may be important reasons for graft incompatibility. Gur et al. [24] studied pear/quince graft combination, and found that cyanogenic glycosides produced by the quince moved across the graft interface, where they were broken down by $\beta$-glycosidase produced by the pear, to liberate cyanide, resulting in the death of graft.

\section{Examining methods for graft union develop- ment and compatibility}

\subsection{Measurement of breaking weight}

Roberts and Brown [25] developed a technique of measuring the force required to break the graft, at different stages after grafting. This can provide a basis for analysis of the progress of the graft over time. Tensile strength is expressed as breaking weight $\left(\mathrm{g} / \mathrm{mm}^{2}\right)$. Studies have showed that during the formation of the graft union, tensile strength can be divided into three stages: (1) At 1-3 d from grafting, tensile strength is little and increases slowly, by $1 \mathrm{~g} / \mathrm{mm}^{2}$ daily, in both compatible and incompatible grafts; (2) tensile strength increases sustainably at 3-11 d, 28 fold in a compatible autograft, reaching a maximum of $56 \mathrm{~g} / \mathrm{mm}^{2}$. In an incompatible graft it increases only at 2-5 d, reaching a maximum of $12 \mathrm{~g} / \mathrm{mm}^{2}$; (3) tensile strength in a compatible graft stabilizes and becomes similar to that of an ungrafted internode, while that of an incompatible graft gradually decreases from day 5. Changes in tensile strength are related to histological and cytological changes within the graft joint [26].

\subsection{Measurements of electrical resistance}

Yang et al. [27] measured changes in electrical resistance at the graft junction in a compatible Lycopersicon esculentum autograft. They found that resistance changes were related to the developmental process of the graft union. Two to 
three days after grafting, the electrical resistance increased rapidly with an isolation layer forming and becoming thicker. In the next 3-8 d, electrical resistance steadily decreased with callus proliferation, the breakage of the isolation layer, formation of secondary plasmodesmata between contacting cells of scion and rootstock, and the differentiation of vascular elements in the callus. Finally, resistance began to drop to the level of the intact stem. However, for an incompatible Amaranthus tricolor/Lycopersicon esculentum heterograft, the electrical resistance at the graft junction was persistently high because of the persistence of the isolation layer.

\subsection{Measurements of hydraulic conductance}

Root hydraulic conductance $\left(L_{0}\right)$ is a measure of nutrient and water absorption in grafted plants; it has therefore been used to determine the graft developmental process [28]. Fernández-García et al. [29] determined the $L_{0}$ value of a Lycopersicon esculentum autograft, 4, 8, 12 and $15 \mathrm{~d}$ after grafting. They found that the $L_{0}$ was zero at day 4 after grafting, then linearly increased and reached a maximum between days 12 and 15. Meanwhile, histological examination found xylem conduits between scion and rootstock at the graft union, and fully developed xylem at day 15 , suggesting that changes in the $L_{0}$ value reflected the xylem developmental process within the graft.

\section{Application of grafting in plant biological re- search}

\subsection{Application of grafting in studies of substance transport}

The formation of vascular bridges between rootstock and scion provides an important developmental index for compatible grafts $[2,15]$. Successful grafting, however, is reflected not only in the structure, but more importantly, in the physiological functions of vascular bridges in the exchange of substances between scion and rootstock. Substance exchange is reciprocal: from scion to rootstock and from rootstock to scion. Assimilate and mineral transport have been commonly used to examine the vascular development of the graft, and the transport functions at the graft union.

Parkinson et al. [30] utilized iron particles with different diameters to detect the transport function of xylem conduits in an explanted stem graft. They found that iron particles were transported with water from rootstock to scion in the compatible autograft of Lycopersicon esculentum and Nicandra physaloides, but not in an incompatible heterograft of Lycopersicon esculentum/Nicandra physaloides. This indicates that graft incompatibility is related to the transport capacity of the xylem at the graft union.

${ }^{14} \mathrm{C}$-labeled assimilates are commonly used to examine the transport function of wound phloem connections between scion and rootstock. De Stigter [31] used ${ }^{14} \mathrm{C}$-labeled $\mathrm{CO}_{2}$ to study assimilate transport in a Silene armeria autograft. They found that transmission from one partner to the others occurred $7 \mathrm{~d}$ after grafting and took place at a high rate by $16 \mathrm{~d}$. The transport of assimilates has been explained in terms of the source-sink concept. Rachow-Brandt and Kollmann [32] studied a compatible heterograft of Lycopersicon esculentum on Solanum tuberosum, and a less compatible heterograft of Vicia faba on Helianthus annuиs. Lycopersicon esculentum, Vicia faba, and Solanum tuberosum homografts served as controls. The transport of ${ }^{14} \mathrm{C}$-labeled assimilates across the graft union started 5-7 d after grafting, in compatible hetero- and homograft combinations. Subsequently, the number of sieve tubes in the graft union and the transport rate of assimilation increased, indicating that assimilate transport is via phloem. For a less compatible graft of Vicia faba on Helianthus annuus, although wound phloem bridges were established between scion and rootstock, only $2 \%$ of assimilates were transported $11 \mathrm{~d}$ after grafting. In comparison, $40 \%$ and $30 \%$ of assimilates in Vicia faba and Helianthus annuus autografts were transported, respectively. Kollmann and Glockmann [22] found that heavy callose was deposited at the sieve pores of an interspecies graft of Vicia faba and Helianthus annuus. The sieve pores thus became narrow; this may, to some extent, have been related to incompatibility. In incompatible grafts, assimilate transport from scion to rootstock is often blocked. Wang and Kollmann [20] determined the assimilate transport of different explanted stem grafts, at different developmental stages, using ${ }^{14} \mathrm{C}$-labeled sucrose. They found that $3 \mathrm{~d}$ after grafting, only a small amount of labeled sucrose was transported from scion to rootstock, possibly by diffusion through secondary plasmodesmata. Five to seven days after grafting, the assimilate transport rate had increased significantly because of the formation of wound phloem bridges between graft partners. In incompatible grafts, because no wound phloem bridge formed between scion and rootstock, the rate of assimilate transport was low, and most assimilates were blocked at the graft union.

6(5)Carboxyfluorescein (CF) has been commonly used to trace substance transport in sieve tubes. Like assimilates, it is also transported from source to sink [33]. Schöning and Kollmann [34] used CF to examine the transport function of wound phloem in an explanted stem autograft of Lycopersicon esculentum and Helianthus annuus, and found that $\mathrm{CF}$ transport was carried out in wound phloem.

Tiedemann and Carstens-Behrens [35] collected phloem exudate from heterografts of Cucumis sativus (scion)/Cucurbita ficifolia or Cucurbita maxima (rootstock) 5-7 weeks after grafting, and examined protein patterns using SDSPAGE. Compared with a Cucurmis control plant, the phloem exudate from the Cucumis scion of the heterografts had at least 4 novel protein bands with molecular weights exactly complementing the Cucurbita protein pattern, includ- 
ing subunits of the PP1 and PP2 proteins within Cucurbita. Golecki et al. [36] further showed that in a Cucurmis sativus scion grafted onto Cucurbita rootstock, at least 9 additional proteins were transported from rootstock to scion, 9-11 d after grafting; indicating that protein exchange occurred in the sieve tubes of scion and rootstock, after phloem reconstruction at the graft union. That the PP1 and PP2 mRNA of the Cucurbita maxima or Cucurbita ficifolia rootstock were undetectable in the Cucurmis sativus scion suggests that proteins rather than mRNA were transported. Cucurbita maxima PP1 was immunolocalized in sieve elements of the extrafascicular phloem of the Cucumis sativus scion, whereas Cucurbita maxima PP2 was found in both the sieve elements and companion cells [37].

\subsection{Application of grafting in studies of long-distance signaling in plants}

Grafting is an ideal method for studying long-distance signaling in plants. Using different combinations of mutants, transgenic plants, and wild-type plants as scion or rootstock, it is possible to analyze reciprocal long-distance signaling mechanisms.

(i) Long-distance transport of RNA through plant phloem. In recent years, studies have found that some RNAs function as non-cell-autonomous signaling molecules, are transported within plants, and control organ development or defense responses. Plant plasmodesmata provide intercellular transport channels for proteins or RNA-protein complexes. The vascular system, the specialized phloem in particular, provides long-distance transport pathways for non-cell-autonomous protein and RNA-protein complexes [38]. Xoconostle-Cázares et al. [39] grafted cucumber (Cucumis sativus) onto pumpkin (Cucurbita maxima), collected sieve exudates from the scion, and analyzed their molecular composition. Their research provided direct evidence that the CmPP16 mRNA of the rootstock was transported to the scion, thus crossing the graft union. Using in situ RT-PCR, Ruiz-Medrano et al. [40] found that $C m N A C P$ mRNA was transported via phloem from pumpkin rootstock into apical tissues of the cucumber scion. CmNACP belongs to NAC domain gene family. Some members of this family are involved in apical meristem development. This experiment confirmed the transport of specific mRNAs to shoot apices in plants. Kim et al. [41] investigated a dominant leaf mutant of tomato called Mouse ears $(\mathrm{Me})$, that is caused by chromosomal rearrangements resulting in a fusion of LeT6 and PEP. If a normal scion is grafted onto a Me mutant rootstock, new leaves that initiate on the scion have the $M e$ morphology. In addition, in situ PCR detected Me transcripts in the scion apex. These findings confirmed that longdistance transport of regulatory mRNAs in plants could control plant morphology. In potato (Solannum tuberosum), the BEL1-like transcription factor StBEL5 and its protein partner POTH1, regulate tuber formation by targeting genes that control growth. Grafting experiments have shown that StBEL5 transcripts could be transported through the graft union to the stolon tips, the site of tuber induction [42]. The above studies indicate that specific RNA molecules can be transported long-distance in plants, via phloem to specific organs, thus regulating plant growth and development.

Recent studies have found that small regulatory RNAs contribute to the complexity of gene regulation. In plants, these RNAs are MicroRNAs (miRNAs) and small interfering RNAs (siRNA) of 21-24 nucleotides in length, functioning as negative regulators of gene expression [43]. Pant et al. [44] found that miR399 could be transported from the scions of overexpressing miR399 to the roots of rootstock wild-type plants. The photoreceptor phytochrome B (PHYB) and the homeodomain protein BEL5, play important roles in the responses of potato tuber induction to the photoperiod. A microRNA, miR172, is involved in this developmental event. The miR172 levels in potato under tuber-inducing short days were observed to be higher than those under noninductive long days, thus promoting tuber formation in the stolon. Tuber formation timing in the graft of $35 \mathrm{~S}:: \mathrm{miR} 172$ scion onto wild-type (WT) rootstock was as early as in the graft of $35 \mathrm{~S}:: \mathrm{miR} 172 / 35 \mathrm{~S}:: \mathrm{miR} 172$ controls, indicating that the effect of miR172 in promoting tuber formation was graft transmissible. In contrast, WT (scion)/35S::miR172 (rootstock) grafts tuberized like WT/WT controls, indicating that overexpression of miR172 in underground parts had no significant promotional effects on tuber formation [45]. Expression of miRNAs was induced under conditions of biotic or abiotic stress [46]. Pi deprivation in Arabidopsis induced expression of miR156, miR399, miR778, miR827, and miR2111, whereas expression of miR169, miR395, and miR398 was repressed [47]. Under sulfur starvation in Arabidopsis, miR395 accumulated within the phloem. hen 1-1 mutants were inhibited in sRNA methylation, resulting in significantly reduced levels of several miRNAs. Buhtz et al. [48] grafted wild-type Arabidopsis with hen 1-1 mutant under sulfur starvation. They observed that the miR395 from the wild-type scion was transported via phloem to hen 1-1 rootstock. Using hen $1-1$ as the scion and the wild-type as rootstock, they failed to observe miR395 transport from rootstock to scion. These experiments have indicated that miR395 is directionally transported from shoot to root. In contrast, miR171 was only detected in the wild-type part of the graft, and not in the mutant part, indicating that it was unable to be transported through the phloem.

(ii) Long-distance transport of signaling protein in plants. Wounding caused by insect or herbivore attack is able to induce systematic responses in higher plants. Specific signals can be delivered from wounds to undamaged sites, causing expression of proteinase inhibitors (PIs). The woundsignaling polypeptide is systemin, composed of 18 amino acids. Systemin is released from its precursor, prosystemin, composed of 200 amino acids [49]. McGurl et al. [50] found that proteinase inhibitors I and II were constitutively ex- 
pressed in the leaves of prosystemin transgenic tomato, but only expressed under wounding in non-transgenic plants. Grafting of non-transgenic tomato plants as scions onto prosystemin transgenic rootstock was able to induce constitutive expression of proteinase inhibitor proteins in the leaves of both scion and rootstock. These results support the proposed role of systemin as the mobile wound signal in plant wound responses.

The transition from vegetative to floral meristems in higher plants depends on the interaction between internal and environmental signals. Florigen is produced in the leaf after inductive photoperiods and transported to the shoot apex where it triggers floral morphogenesis. Genetic studies of Arabidopsis have shown that FLOWERING LOCUS T (FT) can induce long-day and short-day plant flowering [51]. Heterografting has shown that the effective florigenic signal was transported from flowering Cucurbita maxima rootstock to the Cucurbita moschata scion, under long-day conditions. Although real-time RT-PCR detected no FT transcript in the phloem sap collected from the Cucurbita maxima rootstock, Cm-FT L1 and Cm-FT L2 proteins were detectable by mass spectrometry of phloem sap proteins, revealing that Cucurbita maxima FT, and not FT mRNA, is transferred across the graft union in the phloem translocation stream [52]. FT was expressed in the cotyledons and leaves of Arabidopsis under long-day conditions, and induced the target genes such as APETALAl (API) in the shoot apices to initiate floral morphogenesis. Grafting experiments indicated that FT protein was transported from scions to the apical region of the rootstock, suggesting that FT protein rather than its mRNA, is the essential component of florigen [53].

In summary, grafting technology has made important contributions to agriculture for thousands of years. As a unique research system, grafting has been widely used in plant scientific research. Its application has solved some basic theoretical issues such as substance transport and signaling transduction. To resolve new theoretical problems there is a need to select appropriate mutants or transgenic plants, and establish different grafting combinations. However, some issues in grafting still need to be solved. One is how to overcome graft incompatibility, and thus widen its application in agriculture. Another is how to advance monocot grafting technology and utilize it in research involving monocotyledons as model plants.

This work was supported by the National Natural Science Foundation of China (30870140).

1 Yeoman M M, Brown R. Implacations of the formation of the graft union for organisation in the intact plant. Ann Bot, 1976, 40: 1265-1276

2 Yeoman M M, Kilpatrick D C, Miedzybrodzka M B, et al. Cellular interactions during graft formation in plants: A recognition phenomenon? Symp Soc Exp Biol, 1978, 32: 139-160

3 Kollmann R, Yang S, Glockmann R. Studies on graft unions II. Con- tinuous and half plasmodesmata in different regions of the graft interface. Protoplasma, 1985, 126: 19-29

4 Moore R, Walker D B. Studies of vegetative compatibility-incompatibility in higher plants. VI. Grafting of Sedum and Solanum callus tissue in vitro. Protoplasma, 1983, 115: 114-121

5 Moore R. Graft incompatibility between pear and quince: The influence of metabolites of Cydonia oblonga on suspension cultures of Pyrus communis. Am J Bot, 1986, 73: 1-4

6 Gebhardt K, Goldbach H. Establishment, graft union characteristics and growth of Prunus micrografts. Physiol Plant, 1988, 72: 153-159

7 Russo P, Slack S A. Tissue culture methods for the screening and analysis of putative virus-resistant transgenic potato plants. Phytopathology, 1998, 88: 437-441

8 Parkinson M, Yeoman M M. Graft formation in cultured, explanted internodes. New Phytol, 1982, 91: 711-719

9 Wang Y Q. Histologische, cytologische und transport-physiologische Untersuchungen an In-vitro-Pfropflingen unterschiedlicher Kompatibilität. Aachen: Shaker Press, 1992

10 Tsukaya N, Natio S, Rédei G P, et al. A new class of mutations in Arabidopsis thaliana, acaulisI, affecting the development of both inflorescences and leaves. Development, 1993, 118: 751-764

11 Turnbull C G N, Booker J P, Leyser H M O. Micrografting techniques for testing long-distance signaling in Arabidopsis. Plant J, 2002, 32: 255-262

12 Rhee S Y, Somerville C R. Flat-surface grafting in Arabidopsis thaliana. Plant Mol Biol Rep, 1995, 13: 118-123

13 Moore R. Physiological aspects of graft formation. In: Moore R, ed. Vegetative Compatibility Responses in Plants. Waco, TX: Baylor University Press, 1983. 89-105

14 McCully M E. Structural aspects of graft development. In: Moore R, ed. Vegetative Compatibility Responses in Plants. Waco, TX: Baylor University Press, 1983. 71-78

15 Tiedemann R. Graft union development and symplastic phloem contact in the heterograft Cucumis sativus on Cucurbita ficifolia. J Plant Physiol, 1989, 134: 427-440

16 Moore R, Walker D B. Studies of vegetative compatibility-incompatibility in higher plants. I. A structural study of a compatible autograft in Sedum telephoides (Crassulaceae). Am J Bot, 1981, 68: $820-830$

17 Stoddard F L, McCully M E. Histology of the development of the graft union in pea roots. Can J Bot, 1979, 57: 1486-1501

18 Kollmann R, Glockmann C. Studies on graft unions. I. Plasmodesmata between cells of plants belonging to different unrelated taxa. Protoplasma, 1985, 124: 224-235

19 Jeffree C E, Yeoman M M. Development of intercellular connection between opposing cells in a graft union. New Phytol, 1983, 93: 491-509

20 Wang Y, Kollmann R. Vascular differentiation in the graft union of in-vitro grafts with different compatibility-Structural and functional aspects. J Plant Physiol, 1996, 147: 521-533

21 Monzer J, Kollmann R. Vascular connections in the heterograft Lophophora williamsii Coult. on Trichocereus spachianus Rice. J Plant Physiol, 1986, 123: 359-372

22 Kollmann R, Glockmann C. Sieve elements of graft unions. In: Behnke H D, Sjolund R D, eds. Sieve Elements. Comparative Structure, Induction and Development. Berlin, Heidelberg, New York: Springer Press, 1990. 219-237

23 Deloire A, Hébant C. Peroxidase activity and lignification at the interface between stock and scion of compatible and incompatible grafts of Capsicum on Lycopersicum. Ann Bot, 1982, 49: 887-891

24 Gur A, Samish R M, Lifshitz E. The role of the cyanogenic glycoside of the quince in the incompatibility between pear cultivars and quince rootstocks. Hort Res, 1968, 8: 113-134

25 Roberts J R, Brown R. The development of the graft union. J Exp Bot, 1961, 12: 294-302

26 Moore R. Studies of vegetative compatibility-incompatibility in higher plants. IV. The development of tensile strength in a compatible and incompatible graft. Am J Bot, 1983, 70: 226-231

27 Yang S, Xiang G, Zhang S, et al. Electrical resistance as a measure of 
graft union. J Plant Physiol, 1992, 141: 98-104

28 Turquois N, Malone M. Non-destructive assessment of developing hydraulic connections in the graft union of tomato. J Exp Bot, 1996, 47: 701-707

29 Fernández-García N, Carvajal M, Olmos E. Graft union formation in tomato plants: Peroxidase and catalase involvement. Ann Bot, 2004, 93: 53-60

30 Parkinson M, Jeffree C E, Yeoman M M. Incompatibility in cultured explantgrafts between members of' the Solanaceae. New Phytol, 1987, 107: 489-498

31 De Stigter H C M. Parallelism between the transport of ${ }^{14} \mathrm{C}$-photosynthates and the flowering response in grafted Silene armeria L. Z Pflanzenphysiol, 1966, 55: 11-19

32 Rachow-Brandt G, Kollmann R. Studies on graft unions IV. Assimilate transport and sieve element restitution in homo- and heterografts. J Plant Physiol, 1992, 139: 579-583

33 Grignon N, Touraine B, Durand M. 6(5)Carboxyfluorescein as a tracer of phloem sap translocation. Am J Bot, 1989, 76: 871-877

34 Schöning U, Kollmann R. The function of phloem connections in regenerating in vitro-grafts. Bot Acta, 1994, 108: 56-62

35 Tiedemann R, Carstens-Behrens U. Influence of grafting on the phloem protein patterns in Cucurbitaceae I. Additional phloem exudate in Cucumis sativus grafted on two Cucurbita species. J Plant Physiol, 1994, 143: 189-194

36 Golecki B, Schulz A, Carstens-Behrens U, et al. Evidence for graft transmission of structural phloem proteins or their precursors in heterografts of Cucurbitaceae. Planta, 1998, 206: 630-640

37 Golecki B, Schulz A, Thompson G A. Translocation of structural P proteins in the phloem. Plant Cell, 1999, 11: 127-140

38 Yoo B C, Kragler F, Varkonyi-Gasic E, et al. A systemic small RNA signaling system in plants. Plant Cell, 2004, 16: 1979-2000

39 Xoconostle-Cázares B, Xiang Y, Ruiz-Medrano R, et al. Plant paralog to viral movement protein potentiates transport of mRNA into the phloem. Science, 1999, 283: 94-98

40 Ruiz-Medrano R, Xoconostle-Cázares B, Lucas W J. Phloem long-distance transport of CmNACP mRNA: Implications for supra- cellular regulation in plants. Development, 1999, 126: 4405-4419

41 Kim M, Caino W, Kessler S, et al. Developmental changes due to long-distance movement of homeobox fusion transcript in tomato. Science, 2001, 293: 287-289

42 Banerjee A K, Lin T, Hannapel D J. Untranslated regions of a mobile transcript RNA metabolism. Plant Physiol, 2009, 151: 1831-1843

43 Brodersen $\mathrm{P}$, Voinnet $\mathrm{O}$. The diversity of RNA silencing pathways in plants. Trends Genet, 2006, 22: 268-280

44 Pant B D, Buhtz A, Kehr J, et al. MicroRNA 399 is a long-distance signal for the regulation of plant phosphate homeostasis. Plant J, 2008, 53: 731-738

45 Martin A, Adam H, Díaz-Mendoza M, et al. Graft-transmissible induction of potato tuberization by the microRNA miR172. Development, 2009, 136: 2873-2881

46 Sunkar R, Zhu J K. Novel and stress-regulated microRNAs and other small RNAs from Arabidopsis. Plant Cell, 2004, 16: 2001-2019

47 Hsieh L C, Lin S I, Shih A C C, et al. Uncovering small RNA-mediated responses to phosphate deficiency in Arabidopsis by deep sequencing. Plant Physiol, 2009, 151: 2120-2132

48 Buhtz A, Pieritz J, Springer F, et al. Phloem small RNAs. Nutrient stress responses, and systemic mobility. BMC Plant Biol, 2010, 10: 64

49 Ryan C A, Pearce G. Systemin: A polypeptide signal for plant defensive genes. Annu Rev Cell Dev Biol, 1998, 14: 1-7

50 McGurl B, Orozco-Cardenas M, Pearce G, et al. Overexpression of the prosystemin gene in transgenic tomato plants generates a systemic signal that constitutively induces proteinase inhibitor synthesis. Proc Natl Acad Sci USA, 1994, 91: 9799-9802

51 Mouradov A, Cremer F, Coupland G. Control of flowering time: Interaction pathways as a basis for diversity. Plant Cell, 2002, 14: S111-S130

52 Lin M K, Belanger H, Lee Y J, et al. Flowering locus T protein may act as the long-distance florigenic signal in the Cucurbits. Plant Cell, 2007, 19: 1488-1506

53 Noaguchi M, Abe M, Kimura T, et al. Long-distance, graft-transmissible action of Arabidopsis FLOWERING LOCUS T protein to promote flowering. Plant Cell Physiol, 2008, 49: 1645-1658

Open Access This article is distributed under the terms of the Creative Commons Attribution License which permits any use, distribution, and reproduction in any medium, provided the original author(s) and source are credited. 